\title{
Intranasal Delivery of Mesenchymal Stem Cell Exosomes Modulates the Immune Response of Allergic Rhinitis via the MAPK Pathway in a Mouse Model
}

\section{Chenjie Yu}

Nanjing Drum Tower Hospital: Nanjing University Medical School Affiliated Nanjing Drum Tower Hospital https://orcid.org/0000-0002-6734-6247

\section{Yin Chen}

Nanjing Gulou Yi Yuan: Nanjing University Medical School Affiliated Nanjing Drum Tower Hospital

\section{Xinyun Xu}

Nanjing Drum Tower Hospital: Nanjing University Medical School Affiliated Nanjing Drum Tower Hospital

\section{Xin Dou}

Nanjing Drum Tower Hospital: Nanjing University Medical School Affiliated Nanjing Drum Tower Hospital

\section{Shuo Liu}

Nanjing Drum Tower Hospital: Nanjing University Medical School Affiliated Nanjing Drum Tower Hospital

\section{Handong Wang}

Nanjing Drum Tower Hospital: Nanjing University Medical School Affiliated Nanjing Drum Tower Hospital

\section{Xianmei Wei}

Nanjing Drum Tower Hospital: Nanjing University Medical School Affiliated Nanjing Drum Tower Hospital

\section{Zhengrong $\mathrm{Xu}$}

Nanjing Drum Tower Hospital: Nanjing University Medical School Affiliated Nanjing Drum Tower Hospital

\section{Bin Wang}

Nanjing Drum Tower Hospital: Nanjing University Medical School Affiliated Nanjing Drum Tower Hospital

\section{Xinyan Cui}

Jiangsu Province Hospital and Nanjing Medical University First Affiliated Hospital

\section{Xia Gao ( $\nabla$ xiagaogao@hotmail.com )}

The Affiliated Hospital of Nanjing University Medical School 


\section{Research}

Keywords: allergic rhinitis, exosomes, intranasal delivery, MAPK

Posted Date: July 19th, 2021

DOI: https://doi.org/10.21203/rs.3.rs-699167/v1

License: (c) (i) This work is licensed under a Creative Commons Attribution 4.0 International License. Read Full License 


\section{Abstract}

\section{Background}

Allergic rhinitis (AR) is a non-infectious chronic inflammatory disease of the nasal mucosa, which is mainly mediated by IgE after the body is exposed to allergens. It has been shown that transplantation of human mesenchymal stem cells (MSCs) into AR animal models can improve the AR behavioral phenotype. Furthermore, there are recent studies that states exosomes are the main mediators of MSC therapy. However, the effect of exosomes on AR has not been investigated.

\section{Methods}

In the established AR mouse model, different concentrations of MSC-derived exosomes (MSCs-Exo) were applied via intranasal delivery. The AR symptom scores, the eosinophils in the nasal mucosal section, the inflammation infiltration in the spleen section, and IgE, ovalbumin-specific IgE (OVA-slgE), histamine, IgG1, IgG2a and other Th1/Th2 related inflammatory factors were evaluated by Hematoxylin-eosin staining, Elisa, real-time PCR.

Results

We found that intranasal administration of MSCs-Exo could not only reduce the behavior of nasal scratching and sneezing in mice, but also cause a decline in related immune indicators via the MAPK pathway, including the spleen index, tissue staining, and the expression of inflammation-related cytokines. Moreover, we found that the optimal concentration of MSCs-Exo was $4 \times 10^{8} / \mathrm{mL}$.

Conclusion

The significant beneficial effects of exosomes may be exploited to develop a new, non-invasive treatment strategy for AR.

\section{Background}

Allergic rhinitis (AR) is a non-infectious inflammatory disease of the nasal mucosa which is mainly mediated by IgE and driven by Th2 cells after exposure to allergens. The main clinical symptoms are sneezing, a runny nose, nasal itching, and nasal congestion ${ }^{1}$. It has been reported that $10-40 \%$ of adults worldwide suffer from AR, and in developing countries, the situation is even worse, as the number of cases of AR rapidly increased in recent decades, especially in China ${ }^{2}$. The main treatment methods for AR are allergen avoidance, drug therapy, and specific immunotherapy ${ }^{3}$. However, drug therapy can only manage symptoms and cannot reverse or alleviate the immune imbalance. Although specific immunotherapy can desensitize patients to allergens and prevent the development of lesions, it has a long treatment cycle, which tends to result in poor patient compliance and unproductive treatments ${ }^{4}$. Therefore, it is urgent to find new directions for effective treatment. 
Mesenchymal stem cells (MSCs) have the potential for self-renewal and multi-directional differentiation ${ }^{5}$ and have immunomodulatory functions ${ }^{6}$. Previous studies have shown that transplantation of MSCs via the tail vein into an AR mouse model can improve symptoms ${ }^{7,8}$. Xenogeneic MSCs have also been proven to exert similar therapeutic effects in AR mice ${ }^{9}$. In addition, MSCs can also reduce the immunological indicators and adjust the Th1/Th2 reaction balance in AR patients ${ }^{10}$. The application of MSCs has resulted in definite curative effects. However, MSCs have several disadvantages, including vascular obstruction caused by the large cells ${ }^{11}$, unpredictable differentiation in the host ${ }^{12}$, and reported concerns regarding the cancer progression ${ }^{13,14}$.

It has also been proven that exosomes secreted by MSCs (MSCs-Exo) have the same efficacy as MSCs; more importantly, transplantation with its associated risks can be avoided ${ }^{15}$. Exosomes are homogenous vesicles with a diameter of $30-150 \mathrm{~nm}$ secreted by a variety of cells ${ }^{16}$. The vesicles contain different types of proteins, nucleotides, and other substances. Cells can swallow the vesicles through endocytosis so that the active substances in the vesicles can function inside the cells ${ }^{17}$. MSCs-Exo can mimic the functions of MSCs and exert similar immunomodulatory effects ${ }^{18}$. Moreover, exosomes do not have a nuclear structure and cannot be amplified in the host, and thus they are safer in clinical application ${ }^{19}$. However, the clinical use of MSCs-Exo to treat AR has never been investigated. In this paper, we show that AR mice treated with MSCs-Exo by intranasal administration showed a significant improvement in behavior and histology via MAPK signaling.

\section{Methods}

\section{Animals}

Female BLAB/c mice were purchased from Nanjing Medical University and were bred in Nanjing Drum Tower Hospital. All mice were nurtured in ventilated cages and had free access to water and food. The protocols were approved by the Animal Care and Use Committee of Nanjing Medical University and animals were treated following the National Institutes of Health Guide for the Care and Use of Laboratory Animals. All operations were carried out in accordance with the approved procedures.

\section{AR model and MSCs-Exo treatment}

BALB/c mice were sensitized with ovalbumin (OVA) (Sigma-Aldrich, A5503) and aluminum hydroxide gel (Thermo Scientific, 77161) to establish the AR model. At 4 weeks of age, the mice were randomly divided into the control group, the AR group, and the MSCs-Exo treatment group. AR mice were given an intraperitoneal injection of $100 \mu \mathrm{g}$ OVA in $100 \mu \mathrm{l}$ PBS combined with $100 \mu \mathrm{l}$ aluminum hydroxide gel on days 1,5 , and 10 and were treated intranasally with $20 \mu 1$ 10\% OVA in PBS per nostril every day from day 15 to 21. Mice in the control group were given an intraperitoneal injection of $100 \mu$ PBS combined with $100 \mu \mathrm{l}$ aluminum hydroxide gel, and they were treated intranasally with $20 \mu \mathrm{l}$ PBS per nostril every day. Mice in the MSCs-Exo treatment group were given an intraperitoneal injection of $20 \mu \mathrm{g}$ of OVA in $100 \mu \mathrm{l}$ PBS combined with $100 \mu$ l aluminum hydroxide gel on days 1, 5, and 10; were treated intranasally with 20 
$\mu \mathrm{l}$ 10\% OVA in PBS per nostril every day from day 15 to 21; and were treated intranasally with $20 \mu \mathrm{l}$ MSCsExo at different concentrations per nostril every day. Administration was performed using a 10- $\mu \mathrm{L}$ pipette with no anesthetics.

\section{Behavioral tests}

After the last intranasal administration of 10\% OVA on day 21, mice were separately placed in a $10 \times 10 \times 15 \mathrm{~cm}^{3}$ cage. After waiting for $10 \mathrm{~min}$, their symptoms were observed for $10 \mathrm{~min}$. The behaviors that were observed and quantified included nose scratching and sneezing.

\section{Determination of spleen index}

The spleen index was calculated according to the following formula: spleen index $(\mathrm{mg} / \mathrm{g})=$ spleen weight (mg) $\div$ animal body weight $(\mathrm{g})$.

\section{Nasal lavage fluids and serum collection}

At $24 \mathrm{~h}$ after the last intranasal administration, mice were sacrificed by cervical dislocation. PBS (1 ml) was injected into the posterior nostril and a 1.5-mL EP tube was used to collect the nasal lavage fluid at the anterior nostril. The nasal lavage fluid was centrifuged at $2000 \mathrm{rpm}$ for $7 \mathrm{~min}$ at $4^{\circ} \mathrm{C}$ and stored at $-20^{\circ} \mathrm{C}$ until analysis. Blood samples were collected from the orbital venous plexus by capillaries. The blood samples were rested for $60 \mathrm{~min}$, centrifuged at $4000 \mathrm{rpm}$ for $10 \mathrm{~min}$ at $4^{\circ} \mathrm{C}$, and stored at $-20^{\circ} \mathrm{C}$ until analysis.

\section{Isolation of exosomes}

The human umbilical cord was taken from a full-term infant, cut into small pieces, and cultured. Cells were split when the cells reached $80-90 \%$ confluence. In the following procedures, only P5 generation cells were used. After the cells grew to $70 \%$ confluence, the culture medium was discarded, the cells were washed thoroughly with PBS, and the medium was replaced with serum-free medium for $48 \mathrm{~h}$. Next, the conditioned medium was collected, centrifuged at $1000 \times g$ for $20 \mathrm{~min}$ to remove cell debris, and centrifuged at $2000 \times \mathrm{g}$ for $20 \mathrm{~min}$, and the supernatant was filtered using a 220-nm filter. Next, the filtered supernatant was centrifuged at $10,000 \times g$ for $60 \mathrm{~min}$ at $4^{\circ} \mathrm{C}$, and the supernatant was filtered using a 220 -nm filter again. The filtered supernatant was centrifuged at $100,000 \times g$ for $3 \mathrm{~h}$ at $4^{\circ} \mathrm{C}$, the supernatant was discarded, the pelleted exosomes were diluted in $1 \mathrm{ml}$ of pulse medium, and the effective diameter of exosomes was assessed by dynamic light scattering (DLS, Brookhaven Instruments).

\section{Transmission electron microscopy}

For transmission electron microscopy (TEM), exosomes were isolated as described and directly fixed in $200 \mu \mathrm{l}$ of $2 \%$ paraformaldehyde. Exosome preparations $(20 \mu \mathrm{l})$ were allowed to adsorb in a 75 mesh Formvar/carbon coated grid for $30 \mathrm{~min}$ at room temperature. Grids were then washed with PBS 
(membrane side facing down) and dried using a filter paper. TEM was performed using a Hitachi $\mathrm{H}-9000$ transmission electron microscope at $300 \mathrm{kV}$, and images were captured using a slow-scan CCD camera.

\section{RNA extraction and real-time PCR}

The spleen was taken from the sacrificed mice for RNA extraction using TRIzol ${ }^{\mathrm{TM}}$ Reagent (ThermoFisher, 15596026). RNA was reverse transcribed into cDNA using the RevertAid First Strand cDNA Synthesis Kit (Thermo Fisher Scientific, K1622). The concentration and integrity of RNA and cDNA were measured using a NanoDrop (Thermo Fisher, 2000). The mRNA expression values of the genes were normalized to the mRNA expression of actin. The results were calculated using the comparative cycle threshold $(\triangle \triangle \mathrm{Ct})$ method. The primers used were as follows: IL-4(F): GGTCTCAACCCCCAGCTAGT; IL-4(R): GCCGATGATCTCTCTCAAGTGAT; IL-5(F): CTCTGTTGACAAGCAATGAGACG; IL-5(R): TCTTCAGTATGTCTAGCCCCTG; IL-6(F): TAGTCCTTCCTACCCCAATTTCC; IL-6(R): TTGGTCCTTAGCCACTCCTTC; IL-10(F): GCTCTTACTGACTGGCATGAG; IL-10(R): CGCAGCTCTAGGAGCATGTG; IL-13(F): CCTGGCTCTTGCTTGCCTT; IL-13(R): GGTCTTGTGTGATGTTGCTCA; IL-17(F): TTTAACTCCCTTGGCGCAAAA; IL-17(R): CTTTCCCTCCGCATTGACAC; ICAM-1(F): GTGATGCTCAGGTATCCATCCA; ICAM-1(R): CACAGTTCTCAAAGCACAGCG; IFN- $\gamma(F)$ : ATGAACGCTACACACTGCATC; IFN- $\gamma(R)$ : CCATCCTTTTGCCAGTTCCTC; CCL-11(F): GAATCACCAACAACAGATGCAC; CCL-11(R): ATCCTGGACCCACTTCTTCTT; TGF- $\beta 1(F)$ : TCTGCATTGCACTTATGCTGA; TGF- $\beta 1(R)$ : AAAGGGCGATCTAGTGATGGA; TGF- $\beta 2(F)$ : CCGCTGCATATCGTCCTGTG; TGF- $\beta 1(R)$ : AGTGGATGGATGGTCCTATTACA; IKK(F): ACAGCCAGGAGATGGTACG; IKK(R): CAGGGTGACTGAGTCGAGAC; IKB(F): GCGGATGCCGATGAATGGT; IKB(R): TGACGTAGCCAAAGACTAAGGG; JUN(F): CCTTCTACGACGATGCCCTC; JUN(R): GGTTCAAGGTCATGCTCTGTTT; JNK(F): CAGACTGTACCCTCAAGATCCT; JNK(R): ATGCACCCGACAGACCAGA; ERK(F): GGTTGTTCCCAAATGCTGACT; ERK(R): CAACTTCAATCCTCTTGTGAGGG; FOS(F): CGGGTTTCAACGCCGACTA; FOS(R): TTGGCACTAGAGACGGACAGA.

\section{ELISA}

Standard wells and blank wells were set in accordance with the protocol of the Bioswamp ELISA kit. Serum $(40 \mu \mathrm{l})$ was added to each sample well, and $10 \mu \mathrm{l}$ biotinylated antibody and $50 \mu \mathrm{l} \mathrm{HRP-conjugated}$ reagent were added to each well except the blank well. After incubating for $30 \mathrm{~min}$ at $37^{\circ} \mathrm{C}$, washing buffer was added to every well and samples were rested for $30 \mathrm{~s}$ five times. Then, chromogen solution was added to each well and samples were incubated for $10 \mathrm{~min}$ at $37^{\circ} \mathrm{C}$. Lastly, stop solution was added to terminate the reaction and the optical density (OD) at $450 \mathrm{~nm}$ was measured within $15 \mathrm{~min}$.

\section{Hematoxylin-eosin staining}

After mice were sacrificed, their entire heads and spleens were soaked in $10 \%$ neutral formalin fixative for $24 \mathrm{~h}$, because the nasal cavity of BALB/c mice is small. Afterwards, the heads were soaked in $0.5 \mathrm{M}$ 
ethylene diamine tetraacetic acid for decalcification for 4 weeks. After the mouse skull was softened, the tissues were conventionally dehydrated, embedded in paraffin, and sectioned in the coronal position (about $3 \mu \mathrm{m}$ thick slices). The histopathological changes of the nasal mucosa were visualized with hematoxylin-eosin staining. The same steps were applied to the spleens.

\section{Statistical analysis}

At least three independent experiments were performed for each experimental condition. Data were analyzed by GraphPad Prism 5 software and are shown as mean \pm SEM. In addition, two-tailed, unpaired Student $t$-tests were used. Animals were randomly assigned during collection, but the data analysis was single-masked.

\section{Results}

\section{Characterization of MSCs-Exo}

MSCs-Exo have been recognized as a promising substitution for MSCs. Our size distribution analysis revealed that the MSCs-Exo were around $100 \mathrm{~nm}$ in diameter (Figure 1B). TEM analysis of the morphology further confirmed the exosomes' identity (Figure 1A).

\section{Intranasal delivery of MSCs-Exo relieves AR symptoms}

We used an AR mouse model to investigate the role of MSCs-Exo in AR (Figure 2A). We measured the number of sneezing and nose rubbing motions during $10 \mathrm{~min}$ after the last intranasal administration of OVA. The results showed that the mice in the AR group sneezed and rubbed more frequently than those in the control group. Moreover, the numbers of sneezing and rubbing events were significantly lower in the MSCs-Exo treatment group compared to the AR group (Figure 2B). In conclusion, intranasal treatment with MSCs-Exo could notably reduce sneezing and rubbing frequencies, thus indicating that MSCs-Exo could relieve the symptoms in AR mice.

\section{Intranasal delivery of MSCs-Exo reduces AR inflammation}

To further understand the effects of MSCs-Exo on AR, the levels of different inflammation-related indicators were measured. As shown in Figure $2 \mathrm{C}$, sections of the control group revealed normal nasal cavity mucosa. In the AR group, we observed more infiltrating eosinophils and lymphocytes, glandular secretion, and mucosal swelling (Figure 2D). After MSCs-Exo treatment, there were significantly fewer infiltrating cells and less glandular secretion and mucosal swelling in the nasal mucosa (Figure 2E). Additionally, the quantification of eosinophils (Figure 2F) suggested that MSCs-Exo have a therapeutic effect on AR mice. The spleen index, which also reflects the inflammatory status, demonstrated similar differences between the three groups (Figure 3A). Spleen sections from different groups are shown in Figure 3B-D. We observed apparent splenic sinus edema, splenic capsule incrassation, and vasodilation in the AR group (Figure $3 \mathrm{C}$ ), and MSCs-Exo administration reduced inflammation. 
The cytokine levels in the spleen, including Th2 cytokines (IL-4, IL-5, IL-6, IL-10, IL-13, and TGF- $\beta$ ), a Th1 cytokine (IFN-y), a Th17 cytokine (IL-17), an eosinophil chemoattractant (CCL-11) ${ }^{20}$, and an adhesion receptor (ICAM-1) $)^{21}$, were analyzed by RT-PCR at $24 \mathrm{~h}$ after the last treatment. As shown in Figure 4A, IL-4, IL-5, IL-6, IL-13, CCL-11, and ICAM-1 levels were significantly decreased in the MSCs-Exo group compared to the AR group. While there were no differences in IL-17 and TGF- $\beta$ levels, IL-10 and IFN- $\gamma$ levels were obviously enhanced in the MSCs-Exo group compared to the AR group. The serum concentrations of histamine, OVA-lgE, IgE, IgG1, and IgG2a, and the concentrations of histamine, OVA-lgE, and IgG1 in bronchoalveolar lavage fluid (BALF), were measured by ELISA. The MSCs-Exo mice expressed low levels of OVA-lgE, IgE, and IgG1, but not IgG2a (Figure 4B and C). These results verify our hypothesis that intranasal delivery of MSCs-Exo could inhibit allergic airway inflammation and regulate the balance of Th1/Th2 in OVA-sensitized mice.

\section{Optimal concentration of MSCs-Exo}

After clarifying the therapeutic effect of MSCs-Exo, we used different concentrations of MSCs-Exo to find the optimal concentration for AR treatment. We used $4 \times 10^{6} / \mathrm{mL}, 4 \times 10^{7} / \mathrm{mL}, 4 \times 10^{8} / \mathrm{mL}, 4 \times 10^{9} / \mathrm{mL}$, and $4 \times 10^{10} / \mathrm{mL}$ exosomes for intranasal administration in AR mice (Figure $5 \mathrm{~A}$ ). We found that the effect was dose-dependent (Figure 5B-E). At a concentration of $4 \times 10^{6} / \mathrm{mL}$, we observed basically no effect on the sneezing and rubbing events and inflammation-related indicators. At concentrations higher than $4 \times 10^{8} / \mathrm{mL}$, no significant further improvement in the inflammatory symptoms of the mice was observed. This result suggests that the optimal concentration of MSCs-Exo to reduce allergic inflammation in mice is around $4 \times 10^{8} / \mathrm{mL}$.

\section{MSCs-EXO suppress inflammation via the MAPK pathway}

As shown in Figure 6, the mRNA levels of JUN, FOS, ERK, JNK, IKB, and IKK were significantly higher in the AR group than in the control group, while the mRNA levels of JUN, FOS, ERK, and JNK were significantly lower in the MSCs-Exo group than in the AR group but higher than in the control group. Furthermore, there were no differences in the mRNA levels of IKK and IKB between the AR group and the MSCs-Exo group. These results imply that AR might stimulate inflammation by activating the MAPK and NF-KB pathways, while MSCs-Exo alleviates inflammation by inhibiting the MAPK pathway.

\section{Discussion}

We have verified that the AR mouse model was successfully established. We first showed that intranasal delivery of MSCs-Exo could not only relieve the main AR symptoms, sneezing and runny nose, but also decrease various inflammation indicators, including the spleen index, tissue staining, and the expression of inflammation-related cytokines. Moreover, we found that the optimal concentration of MSCs-Exo was $4 \times 10^{8} / \mathrm{mL}$. Besides, we demonstrated that the MAPK and NF-KB pathways play an important role in inflammation, and that MSCs-Exo ameliorated AR by inhibiting the expression of MAPK pathway proteins, which modulated the immune response in the AR mouse model. 
MSCs exert immunoregulatory effects by inhibiting $T$ cell proliferation, inactivating allogeneic $T$ cells, influencing T cell apoptosis ${ }^{22}$, and inhibiting B cell proliferation to decrease antibody secretion ${ }^{23}$. Furthermore, MSCs inhibit the differentiation and maturation of dendritic cells, resulting in a decline in the ability to activate $\mathrm{T}_{\text {cells }}{ }^{24}$. MSCs exert the above immunomodulatory effects mainly through the paracrine secretion of exosomes ${ }^{25}$. The presence of microvilli and columnar cells in the nasal cavity can intensify drug absorption ${ }^{26}$, and intranasal administration is not only safe but also convenient to operate. These advantages increase its feasibility for clinical application. Therefore, we chose to study the therapeutic effect of MSCs-Exo on AR by intranasal delivery; our results verify that intranasal administration of MSCs-Exo works not only locally but also systemically.

After exposure to the specific allergen, IgE mediates mast cell degranulation, causing itching and sneezing and further promoting hemangiectasis and increasing secretion of submucosal glands, thus resulting in obstruction and rhinorrhea. The immunohistological characteristics of AR include the infiltration of eosinophils and the predominant expression of cytokines secreted by Th2 cells, with a reduced activity level of Th1 cells, which contributes to the late-phase response such as nasal obstruction and hyperreactivity 27,28 . Our results correspond with the mechanism underlying AR described above. In the AR model, IgE, OVA-lgE, IgG1, and histamine levels in BALF and serum and Th2 cytokine levels increased, corresponding to severe local and systematic symptoms. After intranasal administration of MSCs-Exo, the decrease in IgE, OVA-lgE, and histamine levels relieved the classic symptoms; the decrease in CCL-11 levels is linked to lower eosinophil infiltration; the change in ICAM-1 and Th2 cytokine levels is linked to reduced inflammation; and increased IFN- $y$ levels can stimulate the expression of IgG2a and inhibit the production of $\lg G 3, \lg G 1, \lg G 2 b$, and $\lg E^{29}$, thus further exerting a therapeutic effect on $A R$. Many studies have also demonstrated that after intravenous treatment with different kinds of exosomes in an asthma mouse model, inflammation of lung tissues decreased, and Th2 cytokine and inflammatory cytokine levels were lower in serum and BALF ${ }^{30-32}$. All these results imply that intranasal delivery of MSCs-Exo has an effect similar to that of intravenous delivery to suppress allergic reactions.

In order to pave the way for clinical application in the near future, we examined the effects of different doses, and found that the optimal concentration is $4 \times 10^{8} / \mathrm{mL}$. When the concentration of MSCs-Exo is lower than $4 \times 10^{8} / \mathrm{mL}$, the efficacy decreases significantly. Once the concentration is higher than $4 \times 10^{8} / \mathrm{mL}$, the curative effects do not further increase significantly. The data show that MSCs-Exo works in a dose-dependent manner, which supports future clinical research.

The activation of NF-KB plays an important role in allergic diseases, inducing the accumulation of inflammatory cells ${ }^{33}$. When activated by inflammatory signals, the released NF-KB induces the transcription of many inflammatory cytokines, which are related to the pathogenesis of asthma ${ }^{34}$. MAPKs are involved in many different cellular events, including allergic diseases ${ }^{35}$. Mammalian MAPKs are mainly divided into three categories: extracellular signal-regulated kinase (ERK), c-Jun N-terminal kinase (JNK), and $\mathrm{p} 38^{36}$. The activation of MAPK is critical for the production of inflammatory cytokines ${ }^{37}$, and functional differentiation into Th1 or Th2 subsets ${ }^{38}$. Notably, inhibition of 
ERK promotes the transition of Th2 lymphocytes to $\mathrm{Th} 1^{39}$. Our results showed that the expression of genes related to the NF-KB and MAPK pathways increased significantly in AR mice, but after MSCs-Exo treatment, the expression of genes related to the NF-KB pathway did not decrease significantly, while MSCs-Exo treatment significantly inhibits ERK, JNK, JUN, and FOS expression. The results confirm that the NF-KB and MAPK pathways play important roles in AR and indicate that MSCs-Exo do not reduce the activation of NF-KB to alleviate the symptoms of AR. MSCs-Exo inhibit inflammation by restricting OVA from affecting the MAPK pathway in AR mice.

While our results have demonstrated that intranasal delivery of MSCs-Exo is an effective therapy for AR, the specific mechanism has not been adequately revealed. It has not been researched how the MAPK pathway regulates the expression of cytokines to play a therapeutic role in AR. The specific functional components of MSCs-Exo have not been identified, and it is unknown how long they remain active. Previously, the effects of intranasal and intravenous delivery of MSCs-Exo on the brain were compared, and intranasal delivery was more effective ${ }^{40}$. For AR, no direct comparisons between intravenous and intranasal delivery have been made. Note also that we only studied intranasal administration of MSCsExo isolated from human umbilical cord; and while this extends the current treatment methods, it will be interesting to test exosomes secreted by other cells to examine the different effects.

Intranasal administration of MSCs-Exo has been researched in various diseases, including complete spinal cord injury ${ }^{41}$, microglia-mediated neuroinflammation ${ }^{42}$, and autism spectrum disorders ${ }^{43}$. It is noteworthy that intranasal delivery of MSC-Exo could substantially expand pulmonary IL-10-producing interstitial macrophages to protect against allergic asthma in mice ${ }^{44}$. However, research on intranasal delivery of MSC-Exo in AR is still scarce. Our results offer a theoretical and experimental basis for the future clinical local application of MSCs-Exo in the nasal cavity for the treatment of AR, which can effectively alleviate pain in AR patients and has significant clinical and social value.

\section{Conclusions}

In conclusion, the effect of exosomes on AR has firstly been investigated in this study, we found that intranasal administration of MSCs-Exo could not only reduce the behavior of nasal scratching and sneezing in mice, but also cause a decline in related immune indicators via the MAPK pathway. The significant beneficial effects of exosomes may provide a new, non-invasive treatment strategy for AR.

\section{Abbreviations}

AR: Allergic rhinitis

MSCs: Mesenchymal stem cells

MSCs-Exo: MSC-derived exosomes

OVA: ovalbumin

Page $10 / 21$ 
OVA-slgE: ovalbumin-specific lgE

TEM: transmission electron microscopy

OD: optical density

BALF: bronchoalveolar lavage fluid

ERK: extracellular signal-regulated kinase

JNK: c-Jun N-terminal kinase

\section{Declarations}

\section{Acknowledgement}

This work was supported by grants from Nanjing Medical Science and Technique Development Foundation (QRX17051, YKK20070) and the Project of Invigorating Health Care Through Science, Technology and Education (ZDXKB2016015). We also thank LetPub (www.letpub.com) for its linguistic assistance during the preparation of this manuscript.

\section{Authors' contributions}

$\mathrm{CY}, \mathrm{YC}, \mathrm{BW}, \mathrm{XC}$, and $\mathrm{XG}$ conceived and designed the experiments. $\mathrm{CY}, \mathrm{YC}, \mathrm{XX}, \mathrm{XD}, \mathrm{SL}, \mathrm{HW}, \mathrm{XW}$ and $Z \mathrm{X}$ performed the experiments. $C Y, Y C, X X, X D, S L, B W, X C$, and $X G$ analyzed the data. $C Y, Y C, B W, X C$, and $X G$ wrote the paper. All authors read and approved the final manuscript.

\section{Funding}

Supported by grants from Nanjing Medical Science and Technique Development Foundation (QRX17051, YKK20070) and the Project of Invigorating Health Care Through Science, Technology and Education (ZDXKB2016015).

\section{Availability of data and materials}

All data generated or analyzed during this study are available from the corresponding author upon reasonable request.

\section{Ethics approval and consent to participate}

The animal procedures were approved by the Animal Care and Use Committee of Nanjing Medical University and animals were treated following the National Institutes of Health Guide for the Care and Use of Laboratory Animals. All operations were carried out in accordance with the approved procedures. All umbilical cord samples were taken after informed and written consent, and the study was approved by the Research Ethics Board of Nanjing Drum Tower Hospital (permit number 2017-161-01). 


\section{Consent for publication}

Not applicable.

\section{Competing interests}

The authors declare no competing interests.

\section{References}

1. Bousquet J, Khaltaev N, Cruz AA, et al. Allergic Rhinitis and its Impact on Asthma (ARIA) 2008 update (in collaboration with the World Health Organization, GA(2)LEN and AllerGen). Allergy. Apr 2008;63 Suppl 86:8-160. doi:10.1111/j.1398-9995.2007.01620.x

2. Zhang Y, Zhang L. Increasing Prevalence of Allergic Rhinitis in China. Allergy, asthma \& immunology research. Mar 2019;11(2):156-169. doi:10.4168/aair.2019.11.2.156

3. Brożek JL, Bousquet J, Agache I, et al. Allergic Rhinitis and its Impact on Asthma (ARIA) guidelines2016 revision. The Journal of allergy and clinical immunology. Oct 2017;140(4):950-958. doi:10.1016/j.jaci.2017.03.050

4. Bernstein DI, Schwartz G, Bernstein JA. Allergic Rhinitis: Mechanisms and Treatment. Immunology and allergy clinics of North America. May 2016;36(2):261-78. doi:10.1016/j.iac.2015.12.004

5. Lee K, Majumdar MK, Buyaner D, Hendricks JK, Pittenger MF, Mosca JD. Human mesenchymal stem cells maintain transgene expression during expansion and differentiation. Mol Ther. Jun 2001;3(6):85766. doi:10.1006/mthe. 2001.0327

6. Zhao ZG, Xu W, Sun L, et al. Immunomodulatory function of regulatory dendritic cells induced by mesenchymal stem cells. Immunological investigations. 2012;41(2):183-98. doi:10.3109/08820139.2011.607877

7. Cho KS, Park HK, Park HY, et al. IFATS collection: Immunomodulatory effects of adipose tissuederived stem cells in an allergic rhinitis mouse model. Stem cells (Dayton, Ohio). Jan 2009;27(1):259-65. doi:10.1634/stemcells.2008-0283

8. Zhao N, Liu Y, Liang $\mathrm{H}$, Jiang $\mathrm{X}$. Bone marrow-derived mesenchymal stem cells reduce immune reaction in a mouse model of allergic rhinitis. American journal of translational research. 2016;8(12):5628-5636.

9. Zhong H, Fan XL, Fang SB, Lin YD, Wen W, Fu QL. Human pluripotent stem cell-derived mesenchymal stem cells prevent chronic allergic airway inflammation via TGF- $\beta 1-S m a d 2 / S m a d 3$ signaling pathway in mice. Molecular immunology. May 2019;109:51-57. doi:10.1016/j.molimm.2019.02.017 
10. Fu QL, Chow YY, Sun SJ, et al. Mesenchymal stem cells derived from human induced pluripotent stem cells modulate T-cell phenotypes in allergic rhinitis. Allergy. Oct 2012;67(10):1215-22. doi:10.1111/j.1398-9995.2012.02875.x.

11. Toma C, Wagner WR, Bowry S, Schwartz A, Villanueva F. Fate of culture-expanded mesenchymal stem cells in the microvasculature: in vivo observations of cell kinetics. Circulation research. Feb 13 2009;104(3):398-402. doi:10.1161/circresaha.108.187724

12. Kuriyan AE, Albini TA, Townsend JH, et al. Vision Loss after Intravitreal Injection of Autologous "Stem Cells" for AMD. The New England journal of medicine. Mar 16 2017;376(11):1047-1053. doi:10.1056/NEJMoa1609583

13. Nishikawa G, Kawada K, Nakagawa J, et al. Bone marrow-derived mesenchymal stem cells promote colorectal cancer progression via CCR5. Cell death \& disease. Mar 19 2019;10(4):264. doi:10.1038/s41419-019-1508-2

14. Jeong JO, Han JW, Kim JM, et al. Malignant tumor formation after transplantation of short-term cultured bone marrow mesenchymal stem cells in experimental myocardial infarction and diabetic neuropathy. Circulation research. May 27 2011;108(11):1340-7. doi:10.1161/circresaha.110.239848

15. Merino-González C, Zuñiga FA, Escudero C, et al. Mesenchymal Stem Cell-Derived Extracellular Vesicles Promote Angiogenesis: Potencial Clinical Application. Frontiers in physiology. 2016;7:24. doi:10.3389/fphys.2016.00024

16. Wortzel I, Dror S, Kenific CM, Lyden D. Exosome-Mediated Metastasis: Communication from a Distance. Developmental cell. May 6 2019;49(3):347-360. doi:10.1016/j.devcel.2019.04.011

17. Bellingham SA, Guo BB, Coleman BM, Hill AF. Exosomes: vehicles for the transfer of toxic proteins associated with neurodegenerative diseases? Frontiers in physiology. 2012;3:124. doi:10.3389/fphys.2012.00124

18. González-González A, García-Sánchez D, Dotta M, Rodríguez-Rey JC, Pérez-Campo FM. Mesenchymal stem cells secretome: The cornerstone of cell-free regenerative medicine. World J Stem Cells. Dec 26 2020;12(12):1529-1552. doi:10.4252/wjsc.v12.i12.1529

19. Huang $B$, Cheng $X$, Wang $H$, et al. Mesenchymal stem cells and their secreted molecules predominantly ameliorate fulminant hepatic failure and chronic liver fibrosis in mice respectively. Journal of translational medicine. Feb 9 2016;14:45. doi:10.1186/s12967-016-0792-1

20. Lilly CM, Woodruff PG, Camargo CA, Jr., et al. Elevated plasma eotaxin levels in patients with acute asthma. The Journal of allergy and clinical immunology. Oct 1999;104(4 Pt 1):786-90.

doi:10.1016/s0091-6749(99)70288-5 
21. Bui TM, Wiesolek HL, Sumagin R. ICAM-1: A master regulator of cellular responses in inflammation, injury resolution, and tumorigenesis. Journal of leukocyte biology. Sep 2020;108(3):787-799. doi:10.1002/jlb.2mr0220-549r

22. Plumas J, Chaperot L, Richard MJ, Molens JP, Bensa JC, Favrot MC. Mesenchymal stem cells induce apoptosis of activated T cells. Leukemia. Sep 2005;19(9):1597-604. doi:10.1038/sj.leu.2403871

23. Corcione A, Benvenuto F, Ferretti E, et al. Human mesenchymal stem cells modulate B-cell functions. Blood. Jan 1 2006;107(1):367-72. doi:10.1182/blood-2005-07-2657

24. Djouad F, Charbonnier LM, Bouffi C, et al. Mesenchymal stem cells inhibit the differentiation of dendritic cells through an interleukin-6-dependent mechanism. Stem cells (Dayton, Ohio). Aug 2007;25(8):2025-32. doi:10.1634/stemcells.2006-0548

25. You HJ, Fang SB, Wu TT, et al. Mesenchymal stem cell-derived exosomes improve motor function and attenuate neuropathology in a mouse model of Machado-Joseph disease. Stem cell research \& therapy. Jun 8 2020;11(1):222. doi:10.1186/s13287-020-01727-2

26. Dahl R, Mygind N. Anatomy, physiology and function of the nasal cavities in health and disease. Advanced drug delivery reviews. Jan 5 1998;29(1-2):3-12. doi:10.1016/s0169-409x(97)00058-6

27. Scadding GK, Kariyawasam HH, Scadding G, et al. BSACl guideline for the diagnosis and management of allergic and non-allergic rhinitis (Revised Edition 2017; First edition 2007). Clinical and experimental allergy : journal of the British Society for Allergy and Clinical Immunology. Jul 2017;47(7):856-889. doi:10.1111/cea.12953

28. Hansen I, Klimek L, Mösges R, Hörmann K. Mediators of inflammation in the early and the late phase of allergic rhinitis. Current opinion in allergy and clinical immunology. Jun 2004;4(3):159-63. doi:10.1097/00130832-200406000-00004

29. Snapper CM, Paul WE. Interferon-gamma and B cell stimulatory factor-1 reciprocally regulate Ig isotype production. Science. May 22 1987;236(4804):944-7. doi:10.1126/science.3107127

30. Xie G, Yang H, Peng X, et al. Mast cell exosomes can suppress allergic reactions by binding to IgE. The Journal of allergy and clinical immunology. Feb 2018;141(2):788-791. doi:10.1016/j.jaci.2017.07.040

31. Zhang HP, Sun YX, Lin Z, et al. CARsomes inhibit airway allergic inflammation in mice by inducing antigen-specific Th2 cell apoptosis. Allergy. May 2020;75(5):1205-1216. doi:10.1111/all.14157

32. Fang SB, Zhang HY, Wang C, et al. Small extracellular vesicles derived from human mesenchymal stromal cells prevent group 2 innate lymphoid cell-dominant allergic airway inflammation through delivery of miR-146a-5p. Journal of extracellular vesicles. 2020;9(1):1723260. doi:10.1080/20013078.2020.1723260 
33. Mishra V, Banga J, Silveyra P. Oxidative stress and cellular pathways of asthma and inflammation: Therapeutic strategies and pharmacological targets. Pharmacology \& therapeutics. Jan 2018;181:169182. doi:10.1016/j.pharmthera.2017.08.011

34. Gagliardo R, Chanez P, Mathieu M, et al. Persistent activation of nuclear factor-kappaB signaling pathway in severe uncontrolled asthma. American journal of respiratory and critical care medicine. Nov 15 2003;168(10):1190-8. doi:10.1164/rccm.200205-4790C

35. Kawakami Y, Hartman SE, Holland PM, Cooper JA, Kawakami T. Multiple signaling pathways for the activation of JNK in mast cells: involvement of Bruton's tyrosine kinase, protein kinase C, and JNK kinases, SEK1 and MKK7. Journal of immunology (Baltimore, Md : 1950). Aug 15 1998;161(4):1795-802.

36. Fang JY, Richardson BC. The MAPK signalling pathways and colorectal cancer. The Lancet Oncology. May 2005;6(5):322-7. doi:10.1016/s1470-2045(05)70168-6

37. Yang SH, Sharrocks AD, Whitmarsh AJ. Transcriptional regulation by the MAP kinase signaling cascades. Gene. Nov 27 2003;320:3-21. doi:10.1016/s0378-1119(03)00816-3

38. Dong C, Yang DD, Tournier C, et al. JNK is required for effector T-cell function but not for T-cell activation. Nature. May 4 2000;405(6782):91-4. doi:10.1038/35011091

39. Yamashita M, Kimura M, Kubo $M$, et al. T cell antigen receptor-mediated activation of the Ras/mitogen-activated protein kinase pathway controls interleukin 4 receptor function and type-2 helper T cell differentiation. Proc Natl Acad Sci U S A. Feb 2 1999;96(3):1024-9. doi:10.1073/pnas.96.3.1024

40. Betzer O, Perets N, Angel A, et al. In Vivo Neuroimaging of Exosomes Using Gold Nanoparticles. ACS nano. Nov 28 2017;11(11):10883-10893. doi:10.1021/acsnano.7b04495

41. Guo S, Perets N, Betzer O, et al. Intranasal Delivery of Mesenchymal Stem Cell Derived Exosomes Loaded with Phosphatase and Tensin Homolog siRNA Repairs Complete Spinal Cord Injury. ACS nano. Sep 24 2019;13(9):10015-10028. doi:10.1021/acsnano.9b01892

42. Thomi G, Surbek D, Haesler V, Joerger-Messerli M, Schoeberlein A. Exosomes derived from umbilical cord mesenchymal stem cells reduce microglia-mediated neuroinflammation in perinatal brain injury. Stem cell research \& therapy. Mar 21 2019;10(1):105. doi:10.1186/s13287-019-1207-z

43. Perets $\mathrm{N}$, Hertz $\mathrm{S}$, London $\mathrm{M}$, Offen $\mathrm{D}$. Intranasal administration of exosomes derived from mesenchymal stem cells ameliorates autistic-like behaviors of BTBR mice. Molecular autism. 2018;9:57. doi:10.1186/s13229-018-0240-6

44. Ren J, Liu Y, Yao Y, et al. Intranasal delivery of MSC-derived exosomes attenuates allergic asthma via expanding IL-10 producing lung interstitial macrophages in mice. International immunopharmacology. Feb 2021;91:107288. doi:10.1016/j.intimp.2020.107288 
Figures

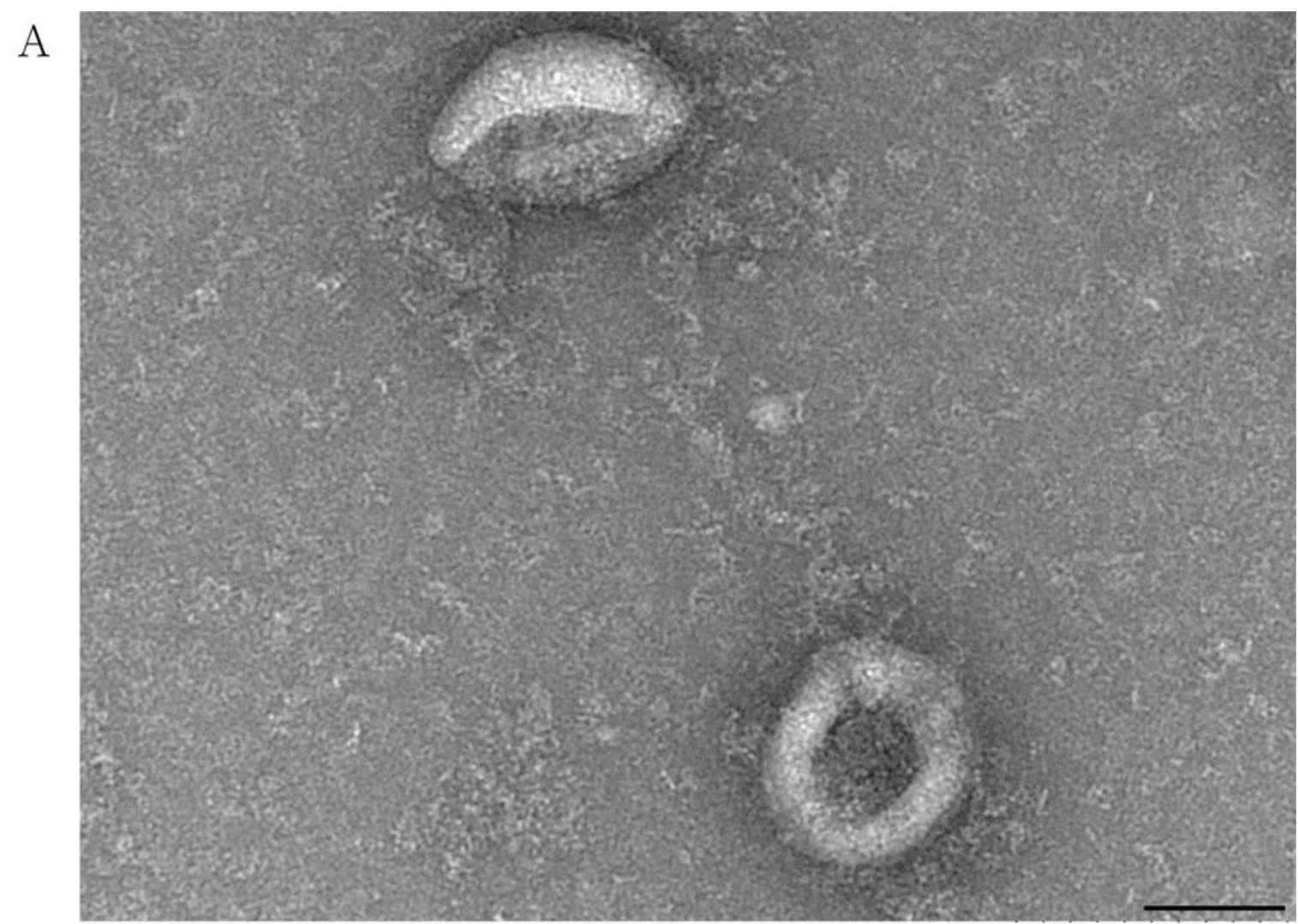

$\mathrm{B}$

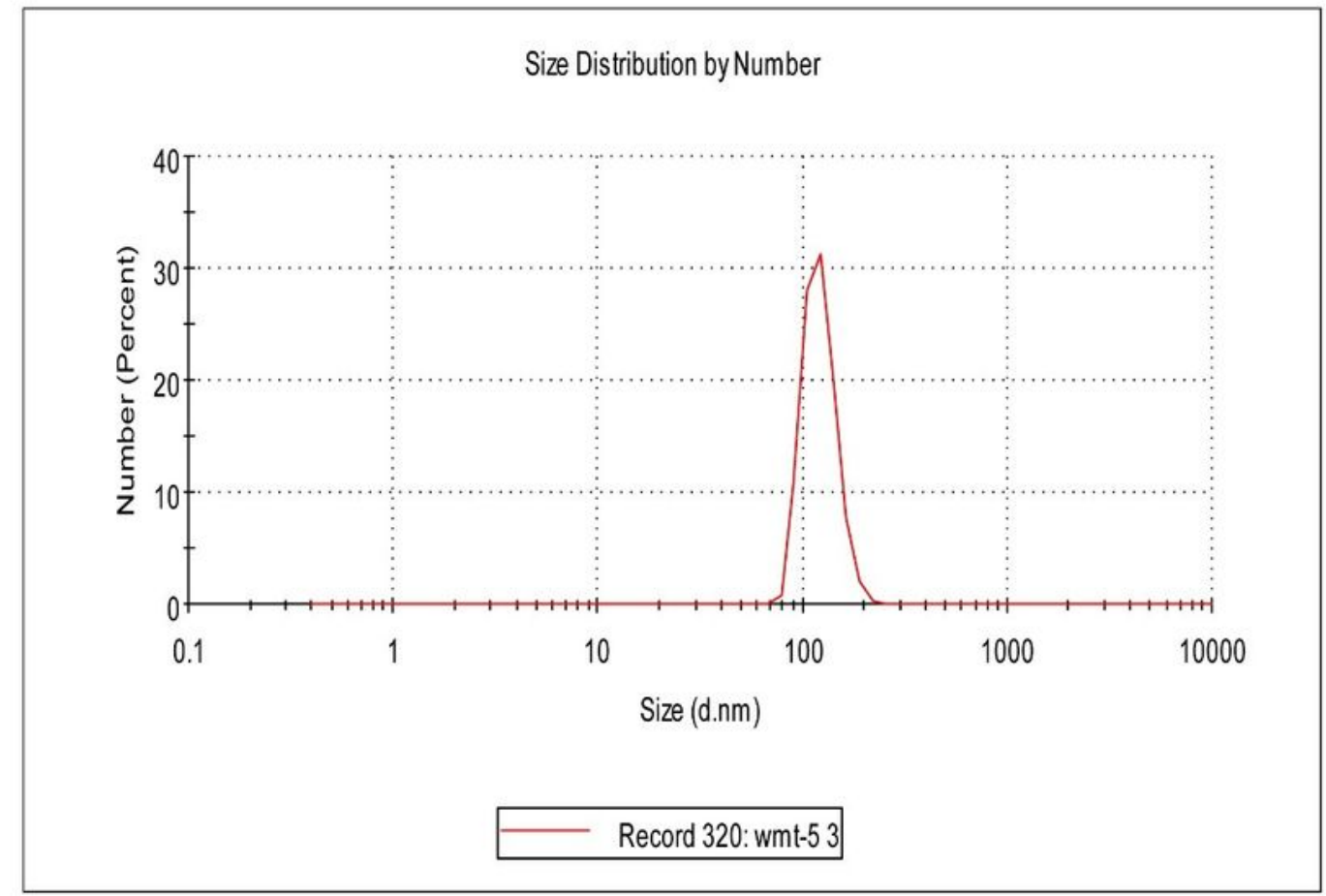

Figure 1

Characterization of MSCs-Exo. (A) Representative TEM (transmission electron microscope) image of the isolated exosomes (scale bar $=100 \mathrm{~nm}$ ). (B) Size distribution curves determined by NTA. 
A

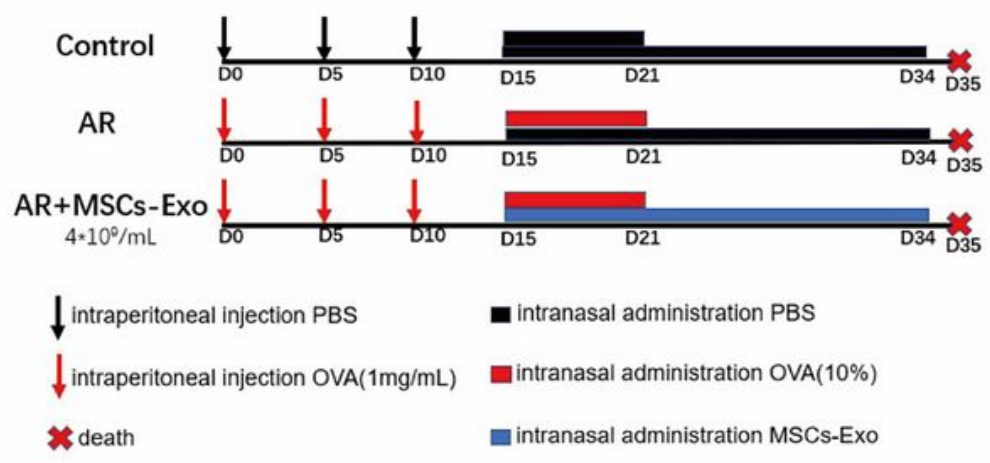

B

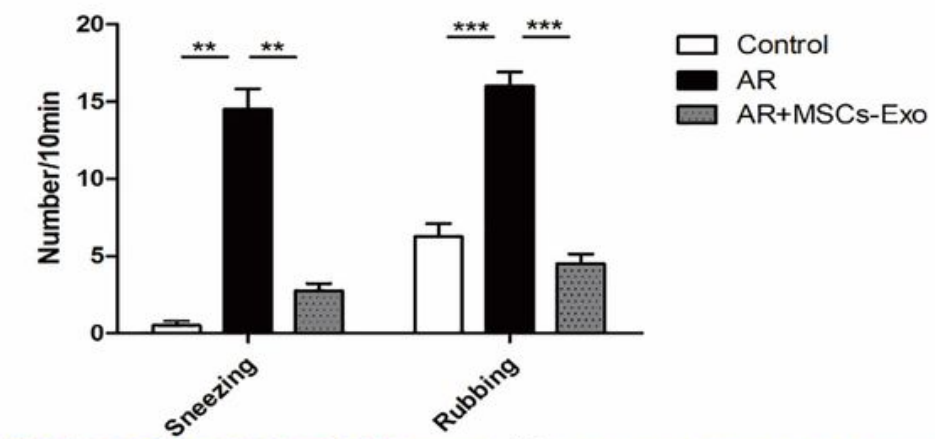

$\mathrm{C}$
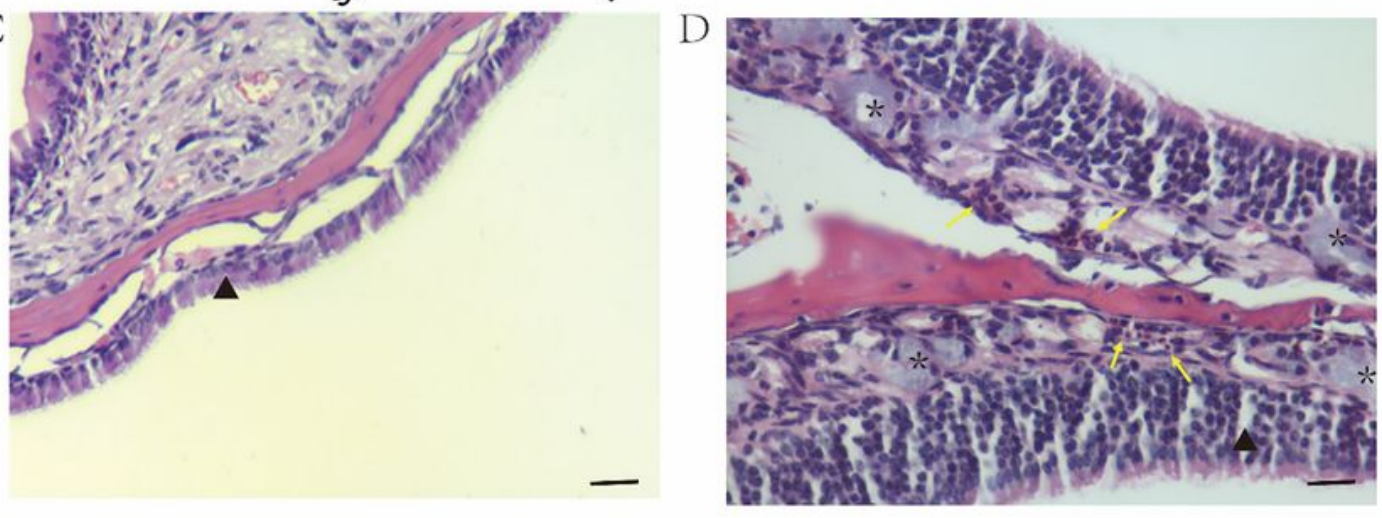

E

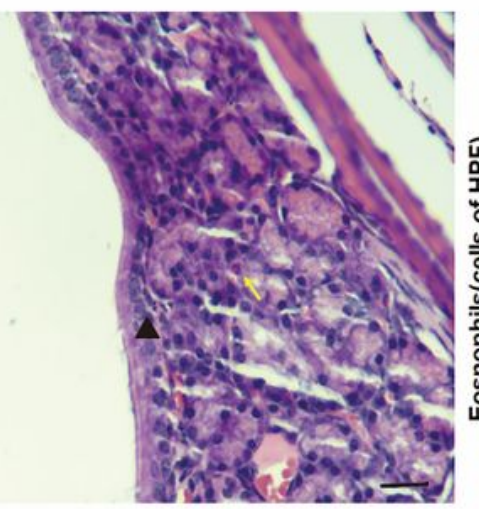

F

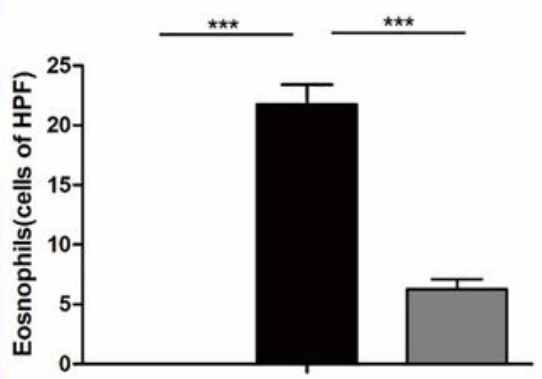

Figure 2

Intranasal delivery of MSCs-Exo relieves AR nasal symptoms during OVA challenge. (A) Experimental outline;(B) Quantification of rubbing and sneezing in different experimental groups; (C-E) HE-stained nasal mucosa sections of BALB/c mice. C: the control group; D: the AR group; E: the MSCs-Exo treatment group. Eosinophils were indicated by yellow arrows. Glands were indicated by black asterisks. Basal cell layers were indicated by black triangles (400 × magnifications; scale bar $=100 \mu \mathrm{m})$. Images are 
representative of 3 independent experiments; $(F)$ Quantification of the numbers of eosinophils under four random $400 x$ magnification field of view $(n=6, * * P<0.01, * * * P<0.001)$.

A

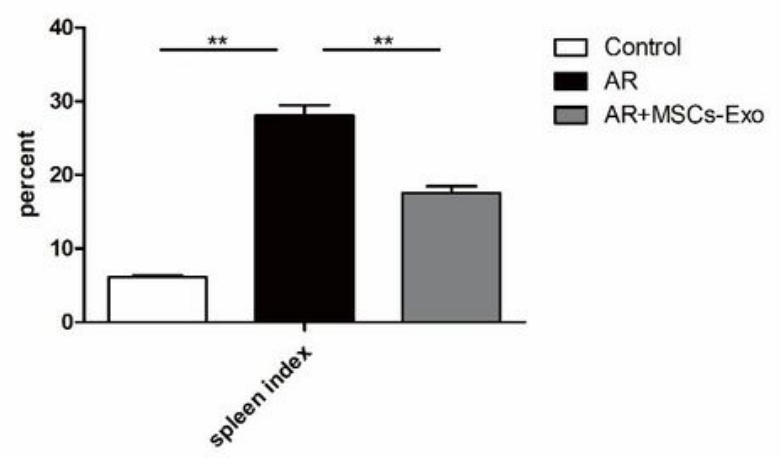

$\mathrm{B}$
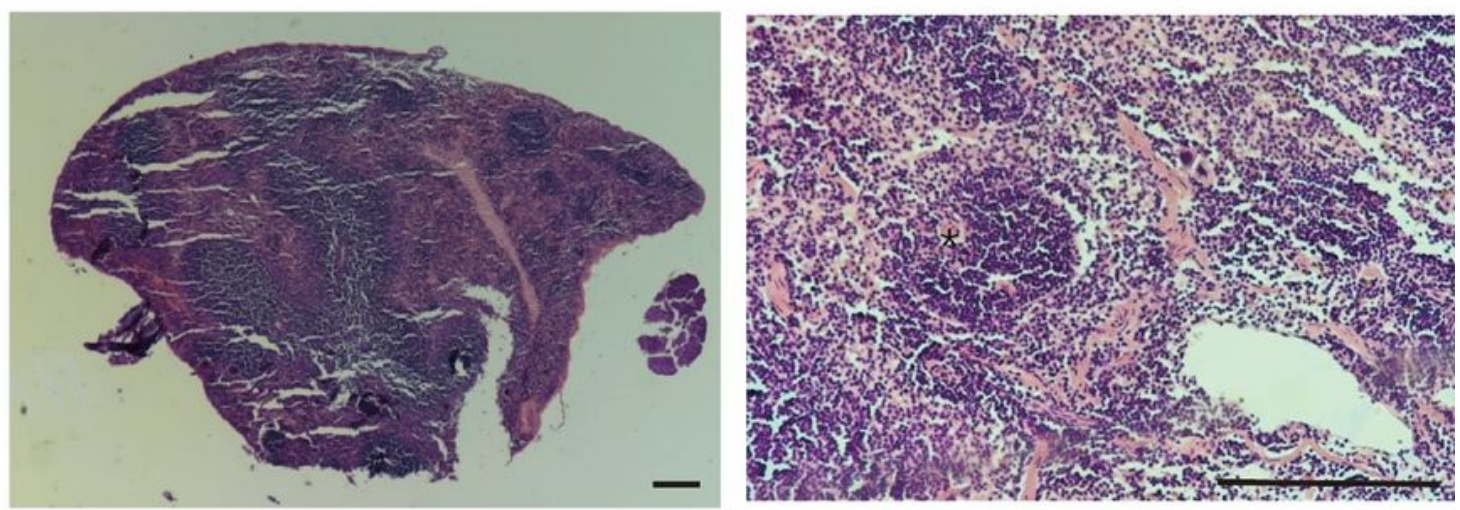

C
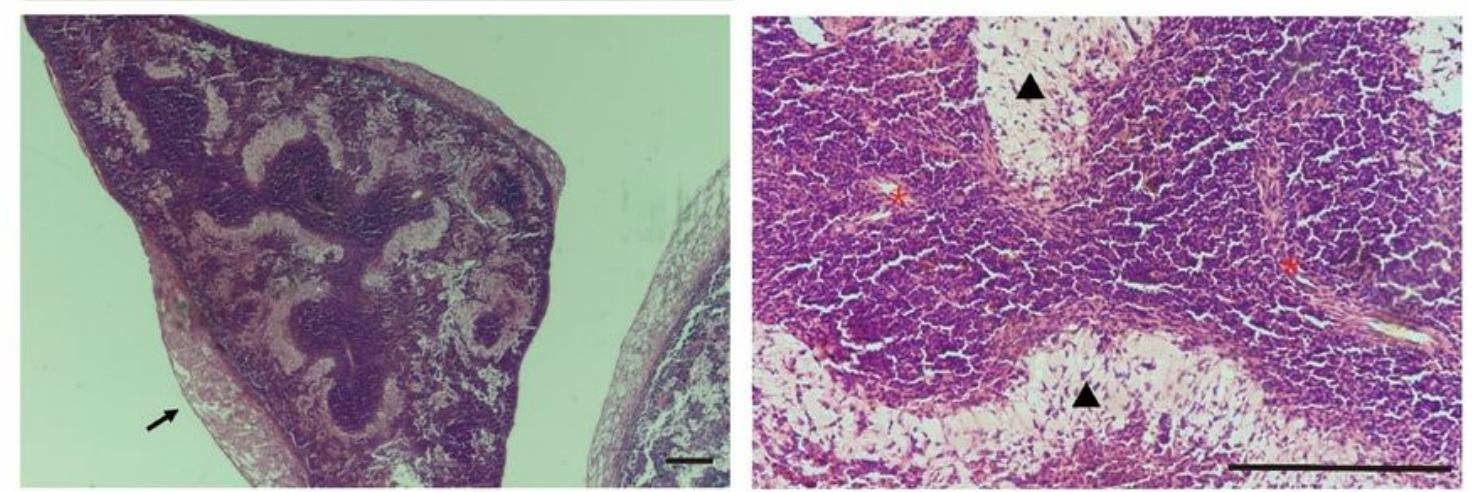

D
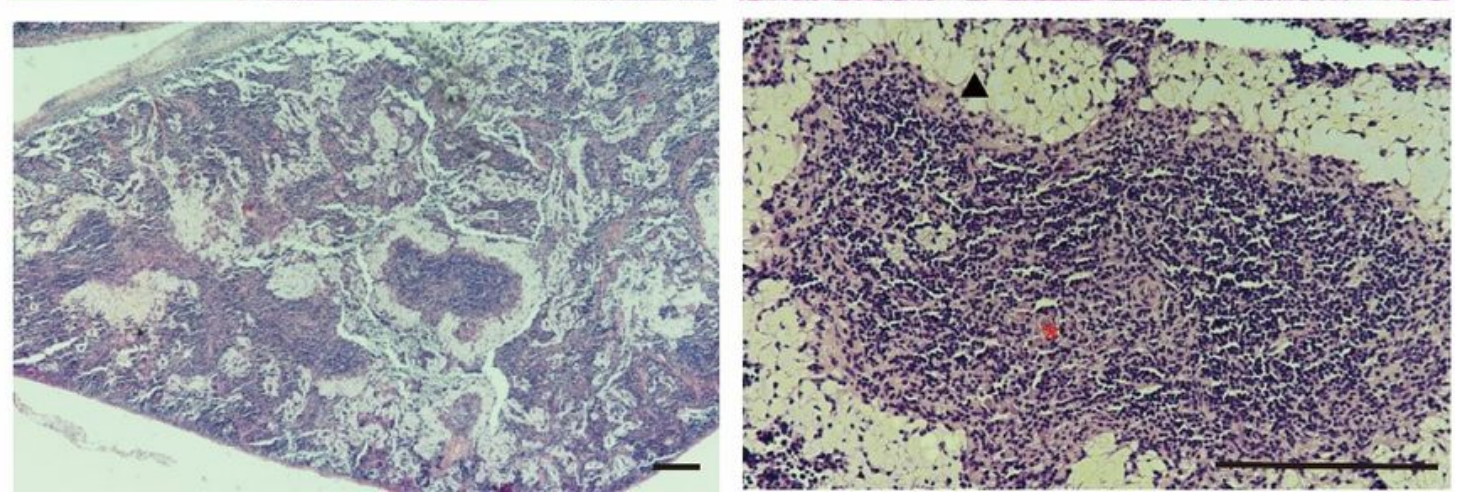

Figure 3

Intranasal delivery of MSCs-Exo reduces inflammation in spleen during OVA challenge. (A) Quantification of the spleen index; (B-D) HE-stained spleen sections of BALB/c mice. B: the control group; C: the AR group; D: the MSCs-Exo treatment group. spleen capsule was indicated by black arrows. Blood vessles 
were indicated by red asterisks. splenic sinus was indicated by black triangles (40x and 200x magnifications; scale bar $=100 \mu \mathrm{m})$. Images are representative of 3 independent experiments $(n=6, * \star P<$ $0.01)$.
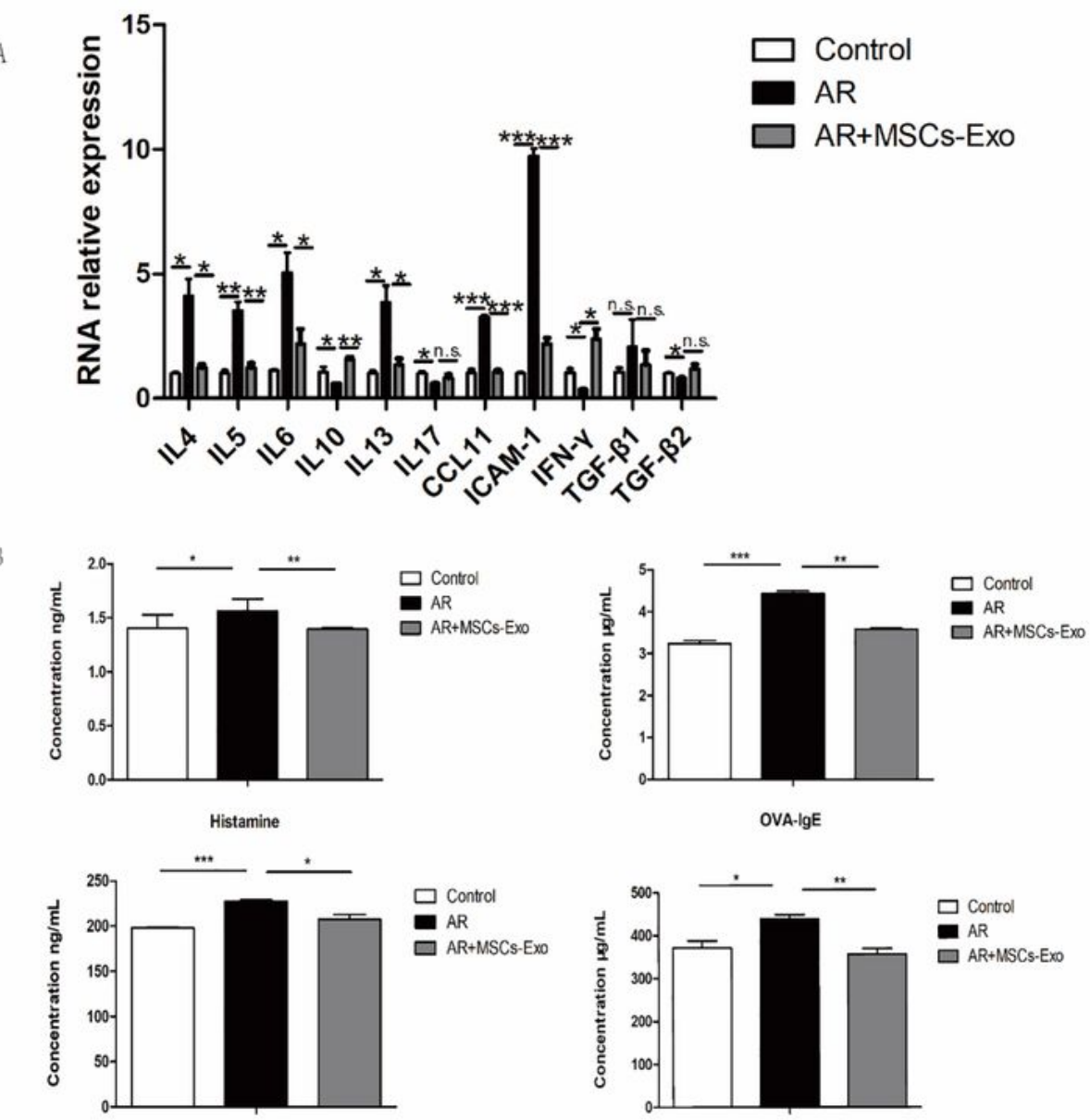

IgE

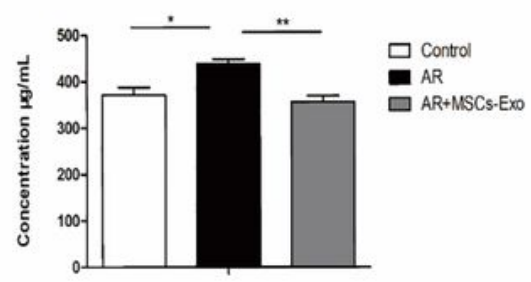

$\lg 61$
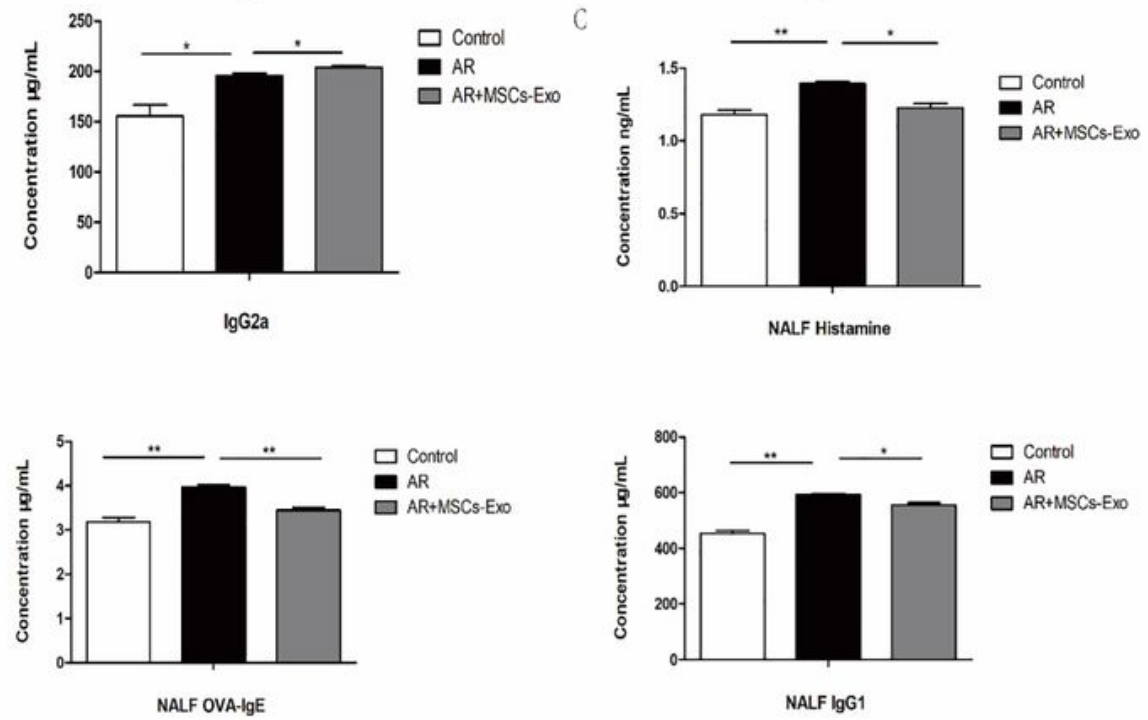

Figure 4

Intranasal delivery of MSCs-Exo reduces Inflammatory biomarkers. (A) RNA relative expression quantification of IL-4, IL-5, IL-6, IL-10, IL-13, IL-17, CCL11, ICAM-1, INF-y and TGF- $\beta$ in spleen following 
different treatments. Four independent QPCR experiments were performed; (B) The protein levels of histamine, OVA-lgE, IgE, IgG1 and IgG2a in sera; (C) The protein levels of histamine, OVA-lgE and IgG1 in NALF ( ${ }^{*} P<0.05,{ }^{*} \mathrm{P}<0.01,{ }^{* \star *} \mathrm{P}<0.001$, n.s., not significant).

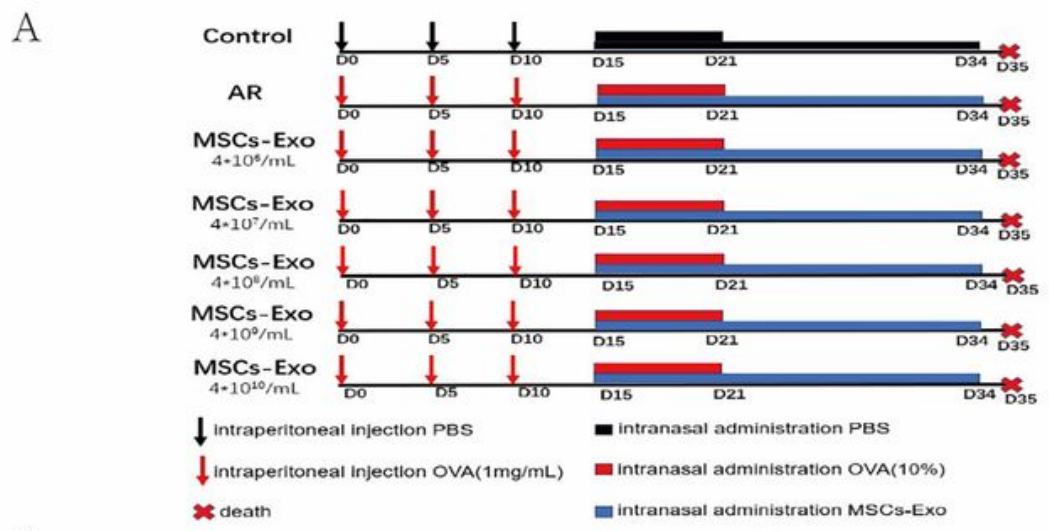

B
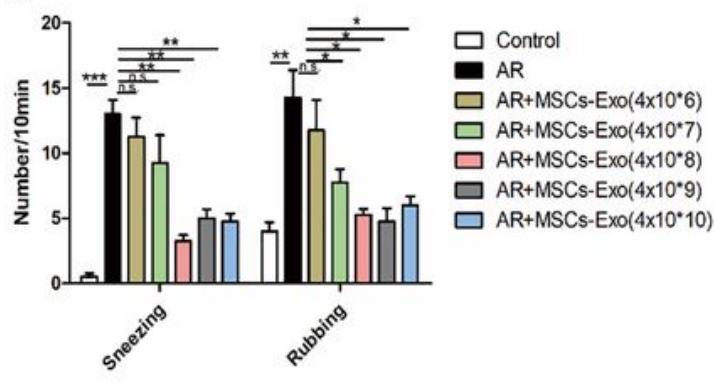

C

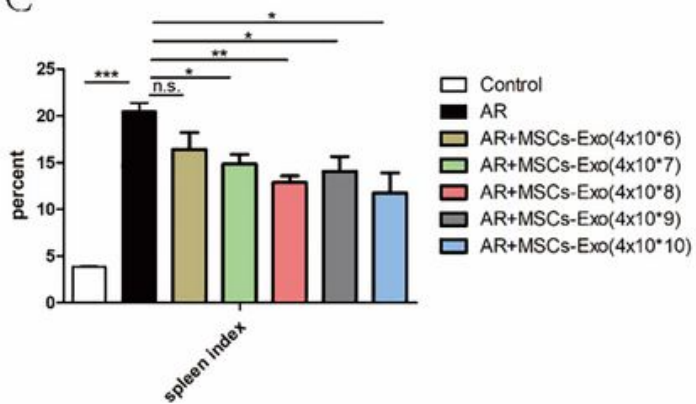

D

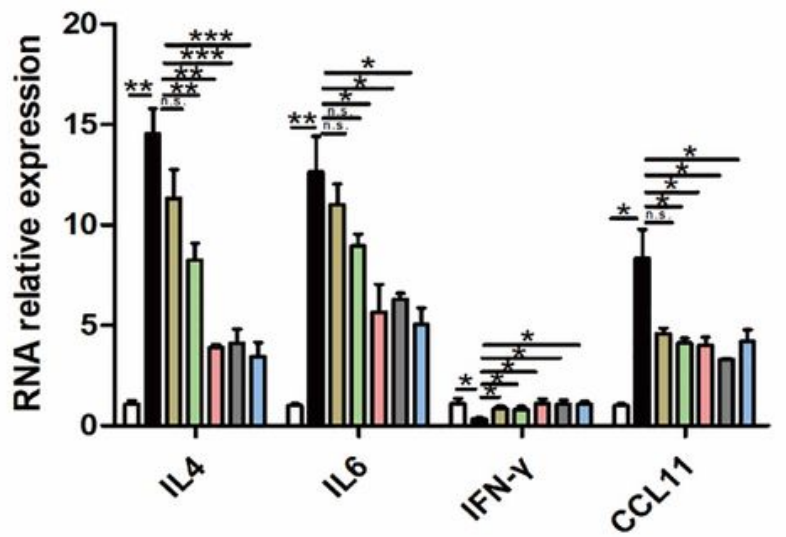

$\square$ Control

aR

$\square$ AR+MSCs-Exo $\left(4 \times 10^{*} 6\right)$

$\square$ AR+MSCs-Exo(4x10*7)

$\square$ AR+MSCs-Exo(4x10*8)

$\square$ AR+MSCs-Exo(4x10*9)

$\square$ AR+MSCs-Exo(4x10*10)

E
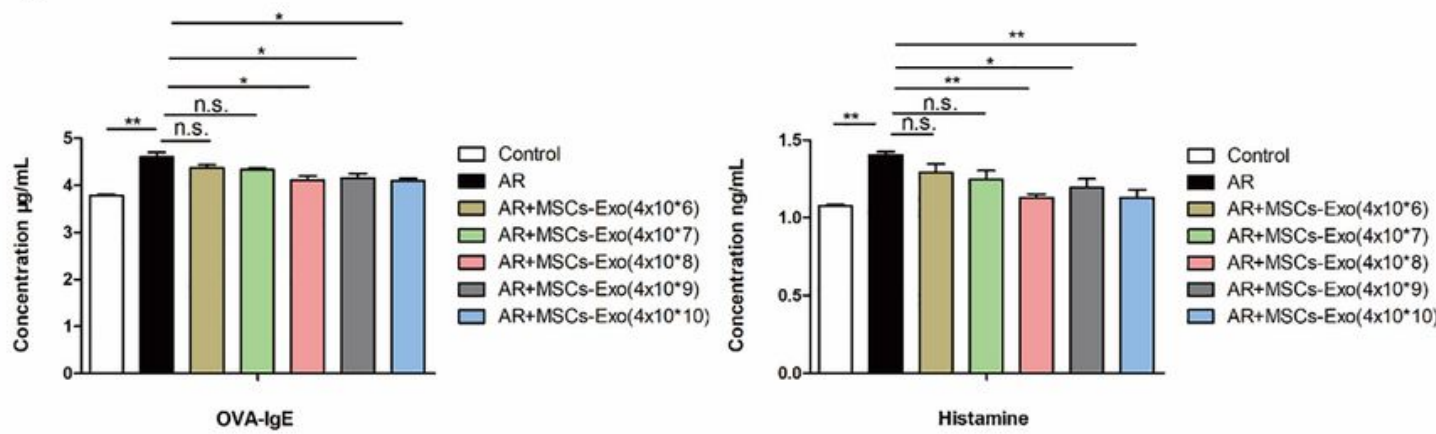

Histamine

Figure 5

The optimal concentration of MSCs-Exo. (A) Experimental outline; (B) Quantification of rubbing and sneezing in different experimental groups; (C) Quantification of spleen index after different treatments; 
(D) RNA relative expression quantification of IL-4, IL-6, INF- $\gamma$ and CCL11 in spleen following different concentrations of MSCs-Exo treatment; (E) The protein levels of OVA-IgE and histamine $\left({ }^{\star} P<0.05,{ }^{\star} \mathrm{P}<\right.$ $0.01,{ }^{\star} * \star \mathrm{P}<0.001$, n.s., not significant).

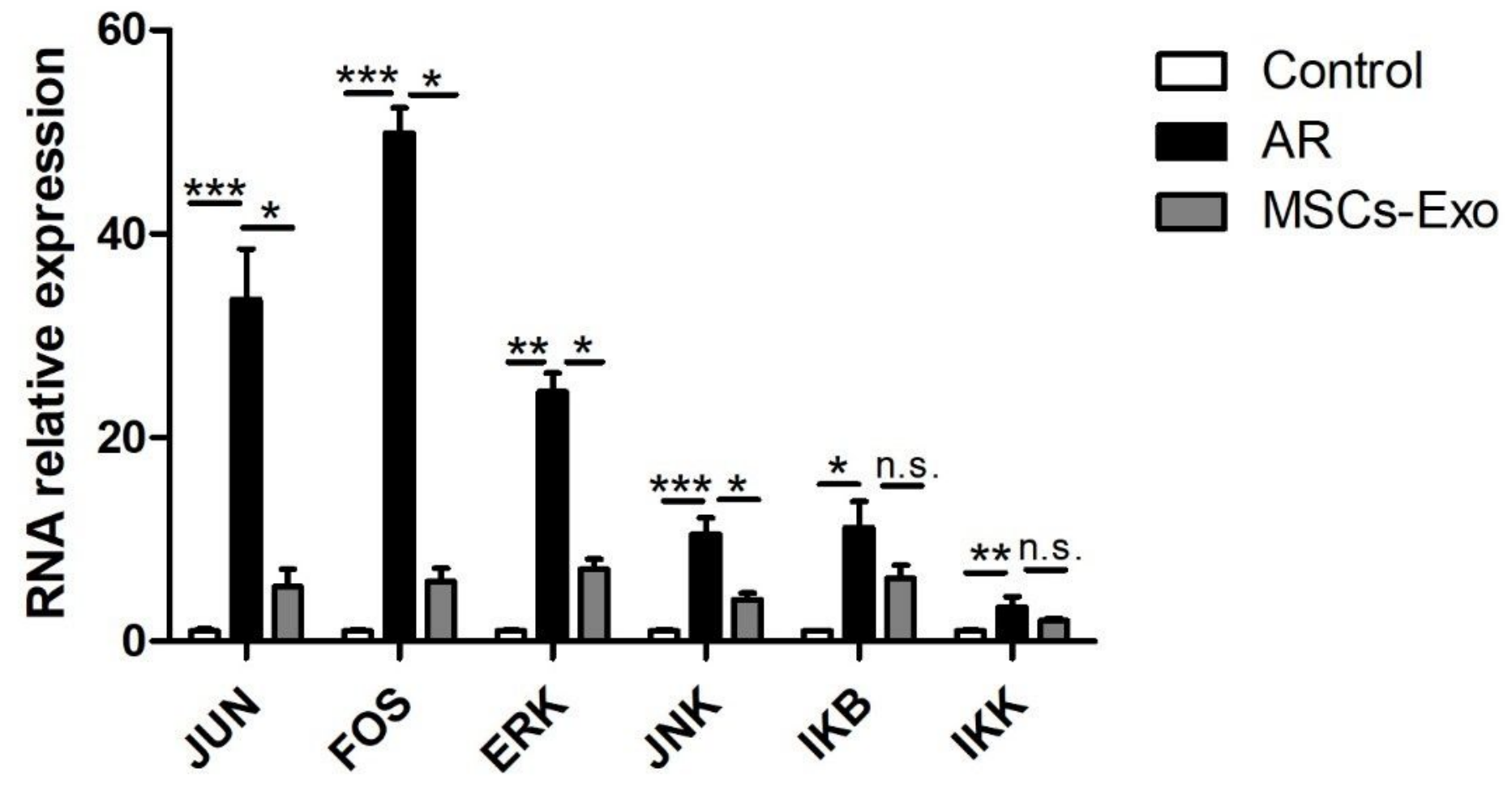

Figure 6

MSCs-EXO suppress the inflammation via the MAPK pathway. RT-PCR results of JUN, FOS, ERK, JNK, IKB and IKK in spleen tissues $\left({ }^{*} p<0.05,{ }^{* \star} p<0.01,{ }^{\star \star *} \mathrm{p}<0.0001\right.$, n.s., not significant). 